\title{
Emergency Control of Sudden Water Pollution Accidents in South to North Water Transfer Project
}

\author{
Guoqing Sang ${ }^{1, a^{*}}$, Ying Wang ${ }^{1, b}$, Shuxin Song ${ }^{1, c}$, Cuiling Jiao ${ }^{2, d}$ and Guoqing \\ $\mathrm{Ma}^{3, \mathrm{e}}$ \\ ${ }^{1}$ School of Resources and Environmental Sciences, University of Jinan, Jinan 250012, China \\ ${ }^{2}$ East Part of South to North Water Diversion in Shandong CO.LTD, JiNan 250013, China \\ ${ }^{3}$ Shandong Province Water Transfer Engineering Technology Research Center, JiNan 250013 , \\ China \\ asangguoqing@163.com, b625645274@qq.com, '625645274@qq.com, d26994016@qq.com, \\ e15866786105@139.com
}

Keywords: South to North Water Diversion Project; Cascade pump station; Water pollution emergency; Emergency control

\begin{abstract}
Taking the cascade pumping station project of the East-Line of South-to-North Water Diversion Project as the research object, the simulation study of sudden water pollution accident and the emergency dispatch control of gate and pump are carried out. The one-dimensional hydrodynamics and water quality numerical model of the cascade pumping station with sudden water pollution accident were established to study the transformation law of pollutant transportation and forecast its impact on water quality. Considering the propagation speed of pollutants and the variation of channel water level, the emergency control mode of pump station and backwater gate under water pollution accident is put forward. On the basis of this, the rules and schemes of pumping station and backwater gates are worked out. The variation range of the pollution group, the variation of the water level of the channel, the discharge quantity and so on under different control schemes are simulated and analyzed. Finally, the optimal pump station and gate scheduling control scheme is selected to effectively control the water pollution accident and ensure the safety of pump stations and channels. The research results can provide technical reference for emergency control of sudden water pollution accident in the east cascade pumping station project.
\end{abstract}

\section{Introduction}

The south of Dongping Lake in the east route of South-to-North Water Diversion Project adopts the 13-stage pumping station to raise the water level one by one. In the event of sudden water pollution accidents, such as improper emergency control, not only may it cause pollution of water diffusion, water disruption, but also it may cause the water level in the channel to change rapidly. Because the pump station is the main control node in the cascade pumping station, the emergency dispatching is different from that of the conventional gravity channel water transfer project. Therefore, in order to effectively deal with the sudden water pollution accident, ensure the water quality and the safety of pump station and channel during the control process, a feasible cascade pumping station emergency control mode must be put forward ${ }^{[1-4]}$ and rules of pump station and controls about regulating lock must be made to seek the most effective, economic and rapid emergency water pollution accident control program.

At present, most of the researches at home and abroad are focused on emergency control of sudden pollution events in open channel water supply projects, and there have few studies on emergency control of water pollution accidents in cascade pumping stations. Xueping $\mathrm{Gao}^{[5]}$ Established the numerical simulation and prediction model of the water level of the Yellow River to Tianjin , debugging on the model several times. The comparison between the results and the measured results shows that the model can predict the water quality of the channel. At the same time, according to the peak of pollutant concentration, the transportation, diffusion and degradation of pollutants were 
analyzed. Dejun Zhu ${ }^{[6]}$ used one-dimensional model to simulate the process of the typical open channel section of the middle route of the South-to-North Water Diversion Project, deducing the propagation velocity of the disturbance in the channel, comparing the pollutant transport in the constant flow and the unsteady flow.

In this paper, taking the cascade pumping station project of the East-line of South-to-North Water Diversion Project as an example, one-dimensional numerical model of hydraulic and water quality of cascade pumping station under sudden water pollution accident is established. Considering the propagation speed of the pollution group and the variation of the water level of the channel, two kinds of emergency control modes are proposed. The control rules and schemes of gates and pumps are established respectively, and the hydraulic response and the effect of water quality control of the two kinds of control schemes are simulated. The parameters such as the diffusion range of the pollution group, the water level variation, the channel water return are analyzed, which can provide technical reference for the sudden water pollution accident treatment of the eastern line of South - to - North Water Diversion Project.

\section{Hydrodynamic and Water Quality Model of Cascade Pumping Station}

In order to study the emergency control problem of cascade pumping station under emergent water pollution accident, a one-dimensional hydrodynamic and water quality simulation model is established. The flow control module is embedded in the hydraulic model to form a simulation platform for water quality emergency dispatching control[7-8]. The platform can accurately predict the transport and transformation of contaminants in water, simulating various emergency control modes and schemes, selecting the optimal control mode and scheme according to the simulation results.

Numerical Model of Cascade Pumping Station Hydraulic. (1) Saint-Venant equation: The Saint-Venant equations of one-dimensional unsteady flow are usually adopted for the hydraulic calculation of long-distance water conveyance channels. The equations are composed of continuity equation and momentum equation:

$$
\begin{aligned}
& \frac{\partial A}{\partial t}+\frac{\partial Q}{\partial x}=q . \\
& \frac{\partial}{\partial t}\left(\frac{Q}{A}\right)+\frac{\partial}{\partial x}\left(\alpha \frac{Q^{2}}{2 A^{2}}\right)+g \frac{\partial Z}{\partial \mathrm{x}}+g\left(S_{f}-S_{0}\right)=0 .
\end{aligned}
$$

Where, $\mathrm{x}$ and $\mathrm{t}$ are space $(\mathrm{m})$ and time coordinate $(\mathrm{s})$; $\mathrm{A}$ is the area of flow $\left(\mathrm{m}^{2}\right)$; $\mathrm{Q}$ is the flow rate $\left(\mathrm{m}^{3} / \mathrm{s}\right) ; \mathrm{Z}$ is the water level $(\mathrm{m})$; $\mathrm{g}$ is the gravitational acceleration $\left(\mathrm{m}^{2} / \mathrm{s}\right)$; $\mathrm{Q}$ is the lateral inflow flow $\left(\mathrm{m}^{3} / \mathrm{s}\right) ; \alpha$ is the momentum correction coefficient; $\mathrm{S}_{0}$ is the channel bottom slope; $\mathrm{S}_{\mathrm{f}}$ is the hydraulic gradient.

(2) boundary conditions and solutions

The one-dimensional Saint-Venant equations are discretized by the preissmann scheme with fast convergence and good stability, and the iterative solution is obtained by the catch-up method. The initial condition is the result of the constant flow model in the normal scheduling model.

Internal boundary conditions are discontinuities in the geometrical shape of the channel or discontinuities in the hydraulic characteristics. For example, the flow pattern is very complex when the water flows through the channel of the hydraulic structure. It is difficult to use a one-dimensional model with simulation and Saint-Venant equation is no longer applicable. So some special treatments must be made according to the hydraulic characteristics. Internal boundary conditions usually contain two compatible conditions: (1) energy conservation conditions. (2) flow continuity conditions. Inner boundary mainly includes the sub-pump station boundary, inverted siphon boundary and control gate boundary. The pumping head unit $\sim$ flow $\sim$ angle equation and the gate-flow equation are treated as coupling conditions, and they are separately solved separately. The pump station boundary is modeled using data from existing pump installations to perform the binomial fitting to the unit performance at 
any angle. $H_{1}-H_{2}=a Q^{2}+b Q+C$. On this basis, the equation is discretized. Where, respectively, $\mathrm{H}_{1}$ is the water side of the water level and $\mathrm{H}_{2}$ is the water level on the inlet side, $\mathrm{a}, \mathrm{b}$, c, respectively, said the pumping station coefficient curve, $\mathrm{Q}$ is the pump station pumping capacity.

Cascade Pumping Station Water Quality Numerical Model. The water quality model of cascade pumping station is described by one-dimensional water quality control equation, the basic equation is as follows

$$
\frac{\partial C}{\partial t}+u \frac{\partial C}{\partial x}=\frac{\partial}{\partial x}\left(E \frac{\partial C}{\partial x}\right)-K C+S
$$

The equation is extended from the one-dimensional river water quality model established by StreatPhelps under steady-state conditions. According to the the basic equation of non-steady-state one-dimensional transformation, the first-order reaction kinetics is used for the source-sink, $S=-K C$. q is the average cross-sectional concentration of the contaminant $(\mathrm{mg} / \mathrm{L})$; $\mathrm{u}$ is the section flow velocity $(\mathrm{m}$ $/ \mathrm{s}$ ). $\mathrm{E}$ is the cross-section of the diffusion coefficient; $\mathrm{K}$ is the pollutant degradation coefficient; $\mathrm{S}$ is the side inflow of pollutants in the amount. In this paper, the water quality model of the cascade pumping station is established by the discrete method based on the equilibrium domain.

\section{Emergency Control Mode and Rules for Cascading Pumping Stations under Sudden Water Pollution}

After a water pollution accident occurs in a cascade canal, the water supply in the accident section should be stopped immediately, and all the water diversion ports in the pumping station and the drainage section in the upper and lower sections shall be closed. The mode of controlling the pollution source in the canal segment and closing it is the control mode of the cascade channel. If the task of water supply is more urgent, in the drainage section within the drainage gate and the external drainage conditions permitting, the sewage through the backwater gate was discharged to the peripheral area. This mode is called efflux control mode[9]. The control rules and constraints for the two control modes are as follows.

Cascade Channel within the Control Rules. Under this control mode, the pumping station control rules of the upstream and downstream canal sections are as follows. Accident channel section: the upstream and downstream pumping station of the accident channel section is shut down in emergency order until it shuts down completely; The upstream section of the accident section: all levels of pumping stations shut down or reduce the flow from top to bottom in order to eventually meet the range of water flow to reach the upper reaches of the cascade flow balance so far to ensure the upper reaches of the accident channel water supply and watershed; Pumping stations at all levels from top to bottom level are closed to stop the water supply and watershed in the downstream channel section of the accident channel.

The following constraints shall be met during the emergency control of the pumping station: (1) The pumping stations shall be shut down for a period of time so that the water level in each section shall be within the limits and the actual conditions of each unit within the pump station shall be taken into account. (2) The closure time of the pumping station at the downstream end of the accident section shall be earlier than the time when the pollutant is transmitted to the pumping station. In addition, in order to prevent the water level of the downstream pump from increasing rapidly, the time for the downstream pump station to shut down may lag behind the time when the upstream pump station starts to shut down.

Efflux Control Rules. Under this control mode, the pumping station control rules of the upstream and downstream canal sections are as follows. Accident cascade channel section: the upstream pump station gradually adjust the flow to the flow of the sluice gate by changing the angle or shutting down the unit. Downstream pump station gradually shut down. The escape gate is opened at the same time to adjust the flow to the design flow. Upstream channel section of the accident channel: all levels of pumping stations to reduce the flow from top to bottom in order to eventually meet the range of water flow and the flow of the upstream pump station to reach the upper reaches of the cascade flow balance, ensuring the water supply of upstream channel in the accident channel; Pumping stations at all levels 
from top to bottom level are closed to stop the water supply and watershed in the downstream channel section of the accident channel.

The following constraints shall be met during the emergency control of the pumping station and the backwater gate: (1) The pumping stations shall be shut down for a period of time so that the water level in each channel section shall be within the limits. (2) The closure time of the pump station downstream of the accident section shall be earlier than the time when the pollutant is transmitted to the pumping station. (3) All the opening time of the backwater gate should be earlier than the time when the pollutant propagates to the control gate.

In order to facilitate the description and calculation, assuming that the flow rate of the upstream pumping station, the backwater gate and the downstream pumping station in the accident section are all linear functions and the flow of the backwater gate and the downstream pumping station are adjusted synchronously to obtain same flows. The control process of the upstream and downstream pumping station and the backwater gate is shown in Fig. 1 Respectively, $t 2$ is the start time of the downstream pump station, $\mathrm{t} 4$ is the start time of the backwater gate, $\mathrm{t} 3$ is the downstream pump station is completely closed, $\mathrm{t} 5$ is the full opening time of the sluice, $\mathrm{Q} 0$ is the initial flow rate, and $\mathrm{Q} 1$ is the final flow rate.

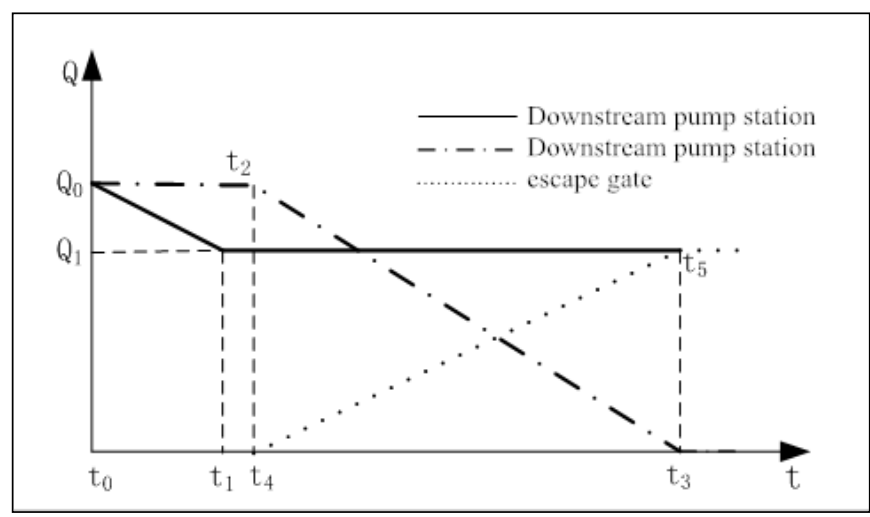

Figure 1. All of a sudden pollution event of canal flow

\section{Simulation and Analysis of Emergency Control for Cascade Pumping Stations}

The cascade pumping stations of the eastern segment of the South-to-North Water Diversion Project in Shandong Province in the two lakes are studied. The upper and lower reaches are Nansi Lake and Luoma Lake. Pumping stations using the original canal and Liu Changhe canal water and water flow is designed to $100 \mathrm{~m} 3 / \mathrm{s}$. The cascade includes three pumping stations: Changgou Pumping Station, Denglou Pumping Station and Baliwan Pumping Station, which are divided into Hukou Changgou, Changgou $\sim$ Denglou and Denglou $\sim$ Baliwan. Due to the surrounding area of Jining coal chemical raw materials, coal chemical raw materials through water and land transport to the south transport. Therefore, in the two lakes along the project there is the risk of coal chemical raw materials into the river because of Rollover, ship leakage accident.

Firstly, the one-dimensional hydrodynamic model of the cascade pumping station is established, and the model parameters are determined by the actual water level and flow data from May to June of 2014. The roughness range of different river sections is 0.018-0.028. According to this, the water quality simulation model is established. Based on the analysis of the risk of sudden water pollution accident in the Hubei and Hubei sections, the high risk accident conditions are as follows: Between Denglou and Changgou Pumping Station, Peng Ying Highway Bridge, the tanker transporting chemical raw material methanol was overturned and leaked into the main channel. The methanol concentration in the tank was $791 \mathrm{~g} / \mathrm{L}$, the leakage event lasted 1 minute, the leakage flow was $12.64 \mathrm{~L} / \mathrm{s}$ and the total leakage was about $600 \mathrm{~kg}$. The diffusion coefficient in the water quality model is taken as $5 \mathrm{~m}^{2} / \mathrm{s}$, and the attenuation coefficient is taken as zero in consideration of the safety of the emergency control ${ }^{[10]}$. The three pumping stations in the two lakes are in the flow equilibrium state at the initial time, and the water flow is $100 \mathrm{~m}^{3} / \mathrm{s}$. Through the establishment of the hydrodynamic and water quality model, the 
simulation of the control scheme in the canal and the outflow is carried out. The parameters such as the diffusion range and the water level variation of the pollution group are calculated. The hydraulic response process and pollution control effect under the two control schemes are analyzed. Finally, the optimal emergency control scheme is determined based on the actual situation.

Simulation Results of Water Quality under Uncontrolled Conditions. After the water pollution accident, in the two lakes section of the pumping station is not controlled, simulation is simulated through the establishment of the cascade pumping station water transfer hydraulics and water quality model to analyze the pollution in the river channel diffusion.(refer with Fig. 2).

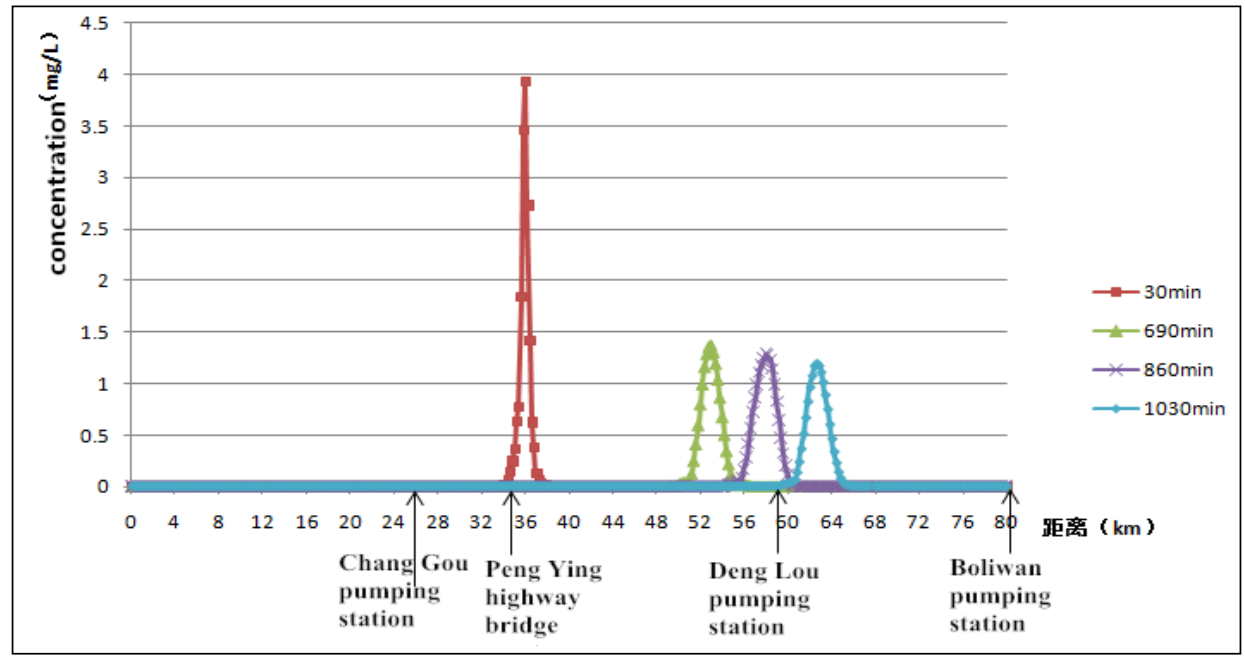

Figure 2. Distribution at different time of pollutants

We can draw a conclusion by the analysis of calculation that under uncontrolled conditions, the pollution will continue to spread to the downstream group, gradually expand the scope of pollution groups and the peak value decreases along the path.

After 1480 minutes, the pollution group reached the Bali Bay pumping station. The peak concentration is $1.037 \mathrm{mg} / \mathrm{L}$, pollution group range is $70.5 \sim 79.2 \mathrm{~km}$, length is $8.7 \mathrm{~km}$, the amount of contaminated water is $1.94 \times 10^{6} \mathrm{~m}^{3}$; and pollution will continue to spread to the downstream movement.

Water Quality Simulation Results of Control Scheme in Channel Section. According to the control rules within the canal to develop control programs, Changgou pumping station and Denglou pumping station are closed in turn. The control scheme is simulated by the establishment of the cascade pumping station water transfer hydraulics and water quality model to analyze the changes in the scope of pollution groups at different times.( refer with Fig. 3)

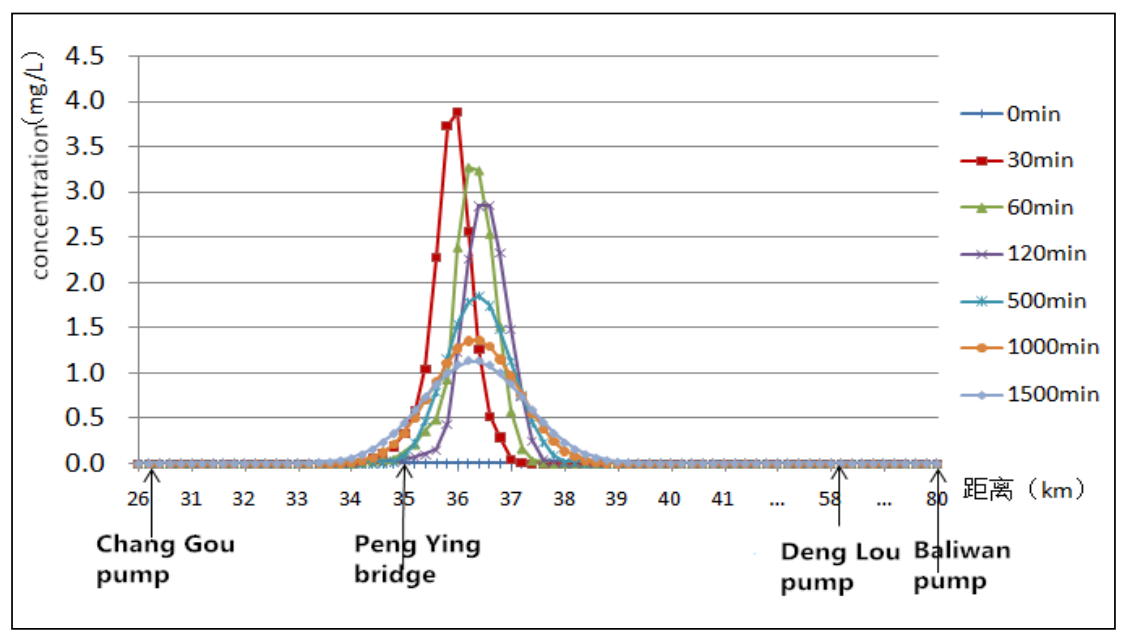

Figure 3. Distribution at different time of pollutants 
From the above calculation results we can see: Denglou and Changgou pumping station in turn are closed. The pollution will continue to spread to the downstream group, gradually expand the scope of pollution groups and the peak value decreases along the path. At 1500 minutes, the pollution mass ranged from 32.6 to $39.8 \mathrm{~km}$, the length was $7.2 \mathrm{~km}$, the peak concentration was $1.129 \mathrm{mg} / \mathrm{L}$, and the total amount of polluted water was $1.6 \times 10^{6} \mathrm{~m}^{3}$. Pollutants were all retained in the accident channel section.

Simulation Results of Water Quality in Efflux Control. The control scheme of pumping station and sluice is developed according to the rules of efflux control. Open Denglou backwater, reduce the Changgou pumping station flow, until consistent with the escape gate flow, close Denglou pumping station. The control scheme was simulated by the hydraulic and water quality model of the cascade pumping station. The range of the pollution group was calculated at different times(refer with Fig. 4).

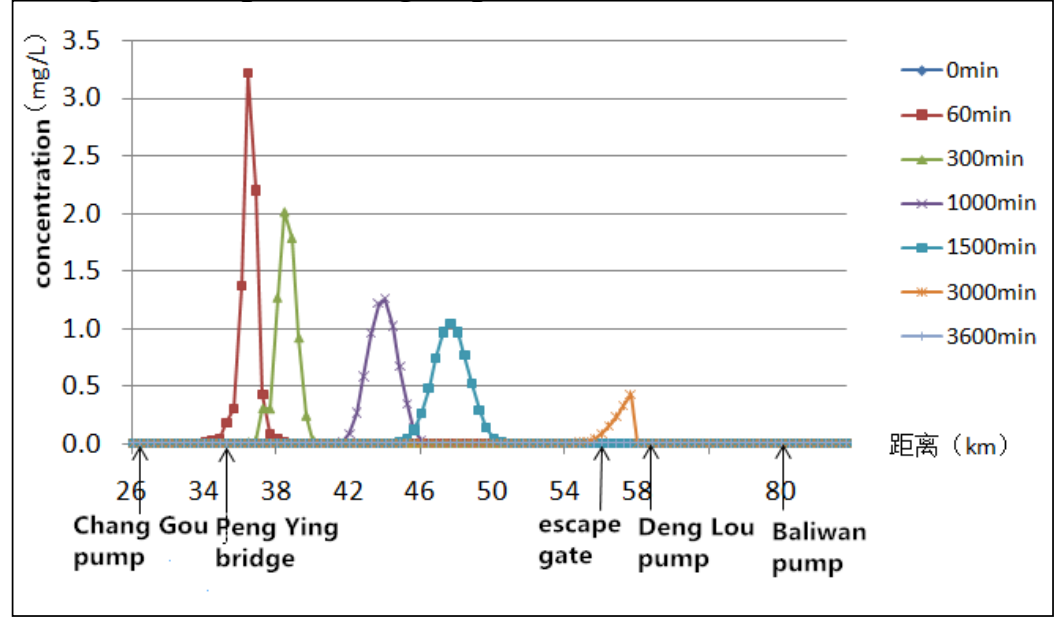

Figure 4. Distribution at different time of pollutants

From the above analysis of the results we can see:

(1) The maximum fluctuation of the water level before and after the Changgou pumping station is $0.235 \mathrm{~m}$ and $0.368 \mathrm{~m}$ respectively. The maximum fluctuation of the water level before and after the Denglou pumping station is $0.342 \mathrm{~m}$ and $0.503 \mathrm{~m}$ respectively, which is less than the luffing level.

(2) With the transport and diffusion of pollution group in the Changgou and Denglou canal section, and the upstream continuous flow of water will gradually replace the drainage section of the polluted water. At 2370 minutes, the front of the pollution group to reach Denglou sluice, in this time pollution group range is $50.2 \sim 57.9 \mathrm{~km}$, the maximum peak is $0.838 \mathrm{mg} / \mathrm{L}$. After 3600 minutes, the polluted water body is replaced by incoming water; the total replacement of water is $6.45 \times 10^{6} \mathrm{~m}^{3}$.

\section{Summary}

Taking the cascade pumping station project of the East-line of the South-to-North Water Diversion Project as an example, an emergency water control model and a water quality model of the cascade pumping station under sudden water pollution accident were established. The emergency control mode and the outflow control mode were proposed. Rules, the corresponding control scheme is developed, and the parameters such as the diffusion range and the water level variation of the pollution group under the two control schemes are simulated respectively, which can provide reference for the emergency control of water pollution accident of cascade pumping station in the east. The main conclusions are as follows:

(1)The use of channels within the control program, the accident section of the upstream and downstream pumping stations are closed with certain rules. The water level fluctuation is always within the allowable range. The program can be closed to pollution in the accident section of the group, the effective control of the spread of pollution groups, in the control process without throwing water.

(2)When the outflow control scheme is adopted, the flow rate of the upstream pump station is adjusted until the flow rate of the backwater gate is the same, and the downstream pumping station is 
closed with certain rules. During the adjustment process, the water level fluctuates within the allowable range. The pollutant mass is firstly sealed in the accident channel section, and then the polluted water body is discharged through the backwater gate by the upstream pumping station.

(3)Both emergency control modes can effectively control the pollution of water bodies, and can ensure the safety of pump stations and channels. The effluent mode can effectively remove the polluted water from the upstream drainage channel, which can shorten the polluted water body, and shorten the period of time. In the actual emergency dispatching, the appropriate emergency control strategy and scheme can be selected according to the initial operating conditions, the characteristics of pollution accidents, the surrounding lagging waters, and so on.

\section{Acknowledgements}

This work was supported by National Natural Science Foundation of China (No.51409119); Project Supported by National Science and Technology Ministry (ID:2015BAB07B03,2015BAB07B02); Water Conservancy research and Technology Promotion Project of Shandong of China (ID:SDSLKY201404);

\section{References}

[1] X.J. Ruan, H.Y. Yuan and C.D. Wang: Design of Irrigation Canal Automatic Control. Journal of Hydraulic Engineering. 35(2004)821-25. (In Chinese)

[2] X. Yao, C.D. Wang and C.J. Li: Operation Mode of Serial Canal System Based on Water Volume Control Method. Journal of Hydraulic Engineering. 39(2008)6,733-738. (In Chinese).

[3] W. Cui, W.X. Chen and X. Yao: Research on Water Level and Flow Cascade Control of Canal. Engineering Journal of Wu Han University. 42(2009)6,764-768. (In Chinese)

[4] S.G. Fang, B.S. Wu and X.D. Fu: Gate Operation in the Middle Route of the South-to-North Water Diversion Channel. Journal of Hydroelectric Engineering. 27(2008)5, 93-97. (in Chinese)

[5] X.P. Gao, C. Zhang and Y. Zhang: Numerical Simulation and Prediction of Water Quality for Water Supply From Yellow River to Tianjin. Chinese Journal of Hydrodynamics. 1(2007)1, 36-43. (In Chinese)

[6] D.J. Zhu: Study on Numerical Methods for Water Pollution Accidents in the Middle Route Open Channel of the South-to-North Water Transfer. (Ph.D, Qinghua University, China 2007).(in Chinese)

[7] J.J. Lian, Z. Zhang and L. Li: Hydraulic Characteristics and Control Approach of Stepped Lowpressurized Water Diversion System with Parallel Multiholes in Regulation Tanks. Journal of Hydraulic Engineering. 37(2006)8,950-957. (In Chinese)

[8] C. Zhang: Study on the Security of Water Quality and Application for Long Distance Water Diversion Project. (Ph.D,Tianjin University, China 2008). (In Chinese)

[9] D.W. Zhang: Research on the key technology of the United regulation of water quality and quantity of the Middle Route of south-to-North Water Diversion. (Ph.D, Dong Hua University, China 2008). (In Chinese)

[10] P.H. Zhang and J.Q. Li: Determine the transverse diffusion coefficient of river linear regression method. Water and electricity energy science. 17(1999)3,117-19. (In Chinese) 